\title{
A Comparative Study of Needlescopic Grasper Assisted Single Incision versus Three-Port versus Pure Single Incision Laparoscopic Cholecystectomy
}

\author{
Chai-Won Kim, M.D., Soo-Ho Lee, M.D., Ph.D., Kee-Hwan Kim, M.D., Ph.D. \\ Department of Surgery, Uijeongbu St.Mary's Hospital, College of Medicine, The Catholic University of Korea, Uijeongbu, Korea
}

Purpose: Single incision laparoscopic cholecystectomy (SILC) is a surgical method to treat gallbladder disease designed to reduce postoperative pain and improve cosmetic results. However, pure SILC (pSILC) has several inherent limitations. In this study, we report the surgical outcomes of SILC with needlescopic grasper (nSILC) compared with those of pSILC and conventional three-port laparoscopic cholecystectomy (TPLC).

Methods: This retrospective study enrolled 103 patients who underwent laparoscopic cholecystectomy for benign gallbladder disease in our hospital between January 2013 and January 2015. Among them, 33 patients underwent pSILC, 35 underwent nSILC, and 35 underwent TPLC. We collected demographic characteristics and operative data to analyze outcomes between groups.

Results: All procedures were done by laparoscopy and the gallbladder of each patient was completely removed. Women and younger patients were more to undergo SILC than TPLC. Analysis showed that the operation time of the nSILC group was longer than that of the TPLC group, but shorter than that of the pSILC group (skin to skin operation time [pSILC: $65.2 \pm 19.1 \mathrm{~min}, \mathrm{nSILC}$ : $49.7 \pm 12.9 \mathrm{~min}$, and TPLC: $43.4 \pm 14.7 \mathrm{~min}, p<0.001$ ], and major procedure time [pSILC: $42.2 \pm 18.7 \mathrm{~min}$, nSILC: $25.9 \pm 8.9$ min, and TPLC: $23.4 \pm 12.7 \mathrm{~min}, p<0.001])$. There were no significant differences between the groups for patient visual analogue scale score, length of hospital stay, or intraoperative blood loss.

Conclusion: nSILC is feasible surgical method in patients with benign gallbladder disease compared to TPLC, and that is an effective procedure to overcome the disadvantage of pSILC.

Keywords: Gallbladder, Cholecystectomy, Laparoscopy
Received June 18, 2019

Revised July 29, 2019

Accepted August 26, 2019

Corresponding author

Kee-Hwan Kim

Department of Surgery, Uijeongbu

St.Mary's Hospital, College of Medicine,

The Catholic University of Korea, 271

Cheonbo-ro, Uijeongbu 11765, Korea

Tel: +82-31-820-3562

Fax: +82-31-847-2717

E-mail: keehwan@catholic.ac.kr ORCID:

https://orcid.org/0000-0001-6219-6027

The findings reported in this article were accepted at the Society of American Gastrointestinal and Endoscopic Surgeons (SAGES) as poster. Also, the abstract of this study was published in the Surgical Endoscopy, April 2018, volume 32, supplement 1 and Korean Association for the Study of the Liver (KASL) 2017, volume 1, p107.

Copyright @ 2019 The Journal of Minimally Invasive Surgery. All rights reserved.

\section{INTRODUCTION}

Laparoscopic cholecystectomy (LC) has been the standard treatment for benign gallbladder disease since $1985 .^{1-3}$ The procedure has been conducted to relieve postoperative pain, improve the length of hospital stay, and reduce scarring of the surgery site in comparison with conventional open cholecystectomy.

Technological advances and development of new surgical instruments have increased minimally invasive surgical methods, including single incision LC (SILC), first published in 1997. ${ }^{1,26}$ However, SILC still has several limitations for the 
surgeon such as repeated conflict between operating instruments, lack of perception caused by the collision of surgical instruments, and reduced visualization of key point for performing the cholecystectomy. To overcome these disadvantages, we used a needlescopic grasper (Minilap Grasper, Stryker, San Jose, CA) for adequate traction of the gallbladder and recovery of instrument triangulation. The procedure was defined as needlescopic grasper-assisted single incision laparoscopic cholecystectomy (nSILC).

The indications for each surgical procedure are similar regardless of whether the case is elective or urgent. ${ }^{6}$ SILC has been mostly used in select patients with exclusion criteria such as obesity, acute cholecystitis, gallbladder empyema, and history of previous abdominal operation. ${ }^{7.8}$ Furthermore, nSILC allows for an expansion of SILC indications to cases with acute inflammation including acute cholecystitis, gangrenous cholecystitis, gallbladder empyema, and obesity. ${ }^{2,7}$

In this study, we aimed to demonstrate the adequacy and operative feasibility of nSILC by comparing the surgical outcomes to pure SILC (pSILC) and conventional three-port laparoscopic cholecystectomy (TPLC).

\section{MATERIALS AND METHODS}

This retrospective study enrolled 103 patients who underwent LC for benign gallbladder disease (gallbladder stone, gallbladder polyp, adenomyomatosis) at Uijeongbu St. Mary’s Hospital, Korea, between January 2013 and January 2015. Among them, 33 patients underwent pSILC, 35 underwent nSILC, and 35 underwent TPLC. All patients were older than 18 years of age who were classified as American Society of Anesthetists (ASA) classification 1 to 3 and excluded emergency gallbladder dis-

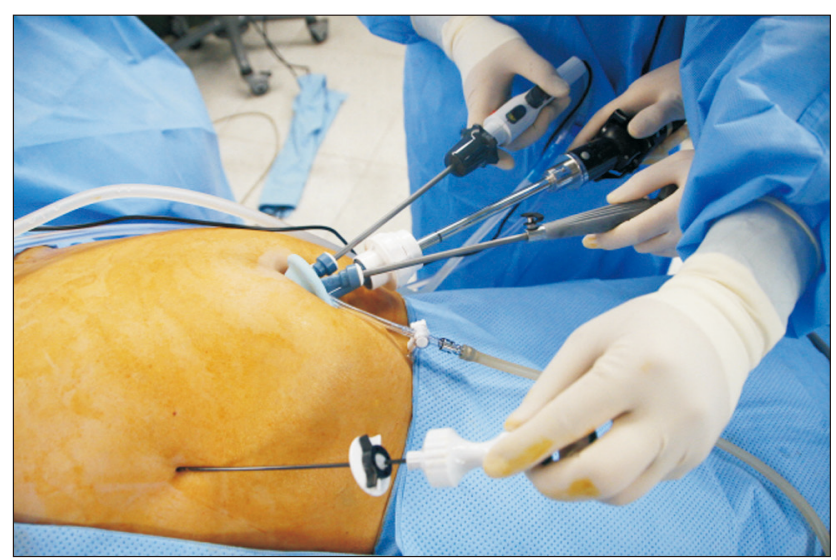

Fig. 1. Needlescopic grasper assisted single incision laparoscopic cholecystectomy (nSILC) nSILC was performed through a SILS port with a snake liver retractor, ENDOPATH ${ }^{\circledR}$ electrosurgery probe plus system, and $2 \mathrm{~mm}$ needlescopic grasper. ease.

We collected patient demographic information and medical data from the patient medical charts including operation time, inoperative blood loss, visual analogue scale score, conversion to open, postoperative complications, ASA classification, and length of hospital stay.

This study was approved by Institutional Review Board (IRB) and assigned study number UC19RESI0068. All analyses were done with IBM SPSS statistics version 13.0 program. Continuous and categorical values were presented as the number (\%) and mean \pm standard deviation. The results were statistically significant difference when the $p$ value was less than 0.05 .

\section{Operation techniques}

\section{Needlescopic grasper assisted single incision laparoscopic} cholecystectomy (nSILC)

The surgical techniques for nSILC were standardized and described in a previous report. ${ }^{1,2}$ Briefly, nSILC was performed routinely through a SILS port (Covidien) with a snake liver retractor for pushing up the hepatic hilum in a cephalad direction and ENDOPATH ${ }^{\circledR}$ electrosurgery probe plus system composed of suction, irrigation unit, and hook electrode for dissection. A snake liver retractor can help to clearly expose the triangle of Calot and shorten the time needed to identify the critical view of safety (CVS). ${ }^{1}$ To get clear visualization of the triangle of Calot and secure the CVS, lateral traction of the gallbladder was performed using an additional $2 \mathrm{~mm}$ needlescopic grasper (Minilap Grasper, Stryker, San Jose, CA)

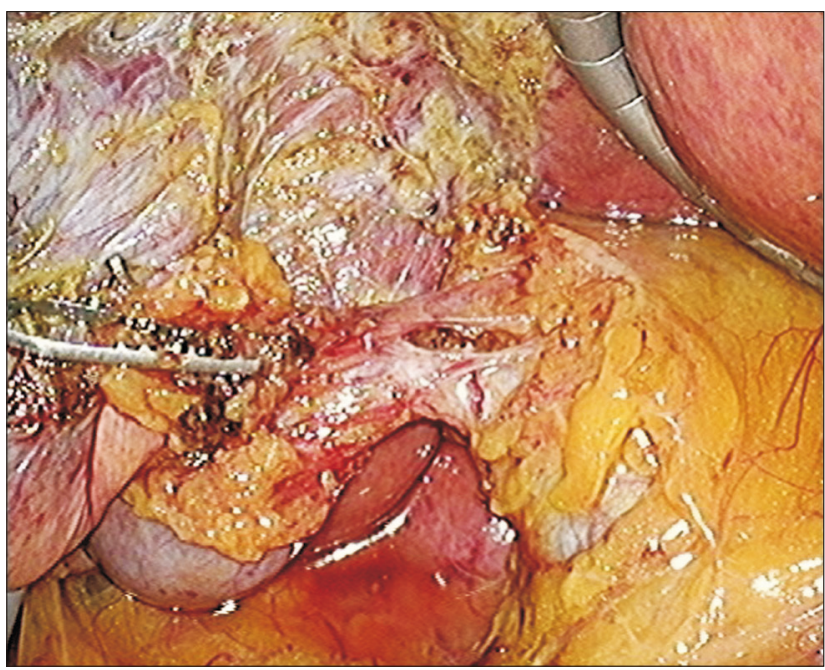

Fig. 2. Needlescopic grasper assisted single incision laparoscopic cholecystectomy (nSILC) to get clear visualization of the triangle of calot and secure the critical view of safety (CVS), lateral traction of the gallbladder was performed using an additional $2 \mathrm{~mm}$ needlescopic grasper. 
which was punctured directly on the right abdomen (Fig. 1, 2). The key point of this technique was to clearly visualize and identify important structures through adequate traction of the gallbladder without crossing or conflicting operating instruments. In almost all cases, CVS could be secured safely by this technique. After achieving CVS, the cystic duct and artery were ligated using a $5 \mathrm{~mm}$ hemolock clip and transected using laparoscopic scissors.

\section{Three-portlaparoscopic cholecystectomy (TPLC)}

TPLC was performed as a routine maneuver using three ports placed at the epigastric, umbilical, and right abdomen area.

\section{Pure single incision laparoscopic cholecystectomy (pSILC)}

This surgical method used articulating instruments (Novare
Surgical, Cupertino, CA, USA) for local triangulation. Retraction was accomplished using endo-retractors (Virtual Ports Ltd., Misgav, Israel). ${ }^{9}$

\section{RESULTS}

Patient characteristics according to surgery group are shown in Table 1. Age was similar between the pSILC group (42.9 \pm 12.3) and the nSILC group ( $41.4 \pm 10.6)$. However, the mean age of patients in the TPLC group $(46.1 \pm 13.5)$ was older than in those in other groups. The pSILC group consisted of 4 male and 29 female patients, the nSILC group consisted of 4 male and 31 female patients, and the TPLC group consisted of 19 male and 16 female patients. Women and younger patients were more likely to undergo SILC over TPLC. The body mass index, diagnosis, and ASA classification were not statistically

Table 1. Characteristics of patients undergoing laparoscopic cholecystectomy

\begin{tabular}{|c|c|c|c|c|}
\hline & pSILC (n=33) & nSILC $(n=35)$ & $\operatorname{TPLC}(n=35)$ & $p$ value \\
\hline Age (years) & $42.9 \pm 12.3$ & $41.4 \pm 10.6$ & $46.1 \pm 13.5$ & $<0.001$ \\
\hline Sex & & & & $<0.001$ \\
\hline Male & $4(12.1 \%)$ & $4(11.4 \%)$ & $19(54.3 \%)$ & \\
\hline Female & $29(87.9 \%)$ & $31(88.6 \%)$ & $16(45.7 \%)$ & \\
\hline Body mass index $\left(\mathrm{Kg} / \mathrm{m}^{2}\right)$ & $25.1 \pm 11.8$ & $26.7 \pm 5.3$ & $24.8 \pm 3.3$ & 0.154 \\
\hline Diagnosis & & & & 0.947 \\
\hline Gallbladder stone & $28(84.8 \%)$ & $31(88.6 \%)$ & $31(88.6 \%)$ & \\
\hline With acute cholecystitis & $5(15.2 \%)$ & $7(20.0 \%)$ & $9(25.7 \%)$ & \\
\hline Without acute cholecystitis & $23(69.6 \%)$ & $24(68.6 \%)$ & $22(62.9 \%)$ & \\
\hline Gallbladder polyp & $2(6.1 \%)$ & $1(2.8 \%)$ & $1(2.8 \%)$ & \\
\hline Adenomyomatosis & $3(9.1 \%)$ & $3(8.6 \%)$ & $3(8.6 \%)$ & \\
\hline ASA classsification $(1 \sim 2 / 3)^{*}$ & $31 / 2$ & $31 / 4$ & $33 / 2$ & 0.608 \\
\hline
\end{tabular}

${ }^{*}$ American Society of Anesthetists classification.

Table 2. Comparision of surgical outcomes between pSILC vs nSILC vs TPLC

\begin{tabular}{lcccc} 
& $\mathrm{pSILC}(\mathrm{n}=33)$ & $\mathrm{nSILC}(\mathbf{n}=35)$ & TPLC $(\mathbf{n}=35)$ & $p$ value \\
\hline Operation time (skin to skin, $\mathrm{min})$ & $65.2 \pm 19.1$ & $49.7 \pm 12.9$ & $43.4 \pm 14.7$ & $<0.001$ \\
Operation time (major procedure $\left.{ }^{*}, \mathrm{~min}\right)$ & $42.2 \pm 18.7$ & $25.9 \pm 8.9$ & $23.4 \pm 12.7$ & $<0.001$ \\
Intraoperative blood loss $(\mathrm{ml})$ & $32.7 \pm 13.7$ & $31.8 \pm 20.8$ & $37.0 \pm 22.0$ & 0.495 \\
Visual analogue scale score & $2.2 \pm 0.8$ & $2.6 \pm 1.4$ & $2.6 \pm 0.9$ & 0.161 \\
Conversion to open & 0 & 0 & 0 & $>0.999$ \\
Postoperative complication & 2 & 1 & 1 & 0.735 \\
Hospital stay (days) & $2.6 \pm 1.6$ & $2.3 \pm 0.9$ & $2.1 \pm 0.5$ & 0.185 \\
\hline
\end{tabular}

* Major procedure = skin to gallbladder removal time from liver bed. 
significant between the groups.

The surgical outcomes of patient groups are shown in Table 2. There were statistical differences between all groups in skin to skin operation mean time (pSILC: $65.2 \pm 19.1 \mathrm{~min}$, nSILC: 49.7 $\pm 12.9 \mathrm{~min}$, and TPLC: $43.4 \pm 14.7 \mathrm{~min}, p<0.001$ ), and major procedure mean time (pSILC: $42.2 \pm 18.7 \mathrm{~min}, \mathrm{nSILC}: 25.9 \pm$ $8.9 \mathrm{~min}$, and TPLC: $23.4 \pm 12.7 \mathrm{~min}, p<0.001)$. The TPLC group mean operation time was shorter than that of the pSILC and nSILC groups.

Between-group comparison results of the visual analogue scale scores (pSILC: $2.2 \pm 0.8$, nSILC: $2.6 \pm 1.4$, and TPLC: 2.6 $\pm 0.9, p=0.161$ ), length of hospital stay (pSILC: $2.6 \pm 1.6$, nSILC: $2.3 \pm 0.9$, and TPLC: $2.1 \pm 0.5, p=0.185$ ), and intraoperative blood loss (pSILC: $32.7 \pm 13.7$, nSILC: $31.8 \pm 20.8$, and TPLC: 37.0 $\pm 22.0, p=0.495)$ were not statistically different.

\section{DISCUSSION}

Since 1985, LC has been an important development in general surgery. As minimally invasive laparoscopic surgery is preferred, SILC was introduced in the 1990s. ${ }^{3}$ SILC is less invasive as it requires fewer ports than TPLC., ${ }^{1,2,10}$ Moreover, pSILC was a surgical option with the goal of reducing postoperative pain and improving cosmetic effect with non-visible scar. However, pSILC has some difficulties because of the limitation of obtaining a CVS and inappropriate traction of the gallbladder. Surgeons have used a snake liver retractor and needlescopic grasper to overcome unclear exposure of the triangle of Calot. ${ }^{2}$ This technique is nSILC and was allowed for CVS due to needlescopic grasper for lateral traction and snake liver retractor for cephalad space traction of gallbladder during SILC. ${ }^{1}$ At present, a comparative study of three surgical methods is needed.

This study was performed to compare the surgical outcomes of nSILC, pSILC and TPLC. There were no significant differences in pain according to visual analogue scale score, length of hospital stay, or postoperative complications, while gender, age, and operative time showed significant differences between groups.

The mean age was similar between the pSILC and nSILC groups, but TPLC group was older than the other groups. It can be seen that young people prefer SILC. In terms of gender composition, women prefer SILC to men.

It is generally known that pSILC is a more desirable method for patients than TPLC because of the reduced postoperative pain. ${ }^{3,5,11,12}$ In contrast, a systematic review reported no statistically significant difference in postoperative pain scores for pSILC versus 4-Port LC. ${ }^{6}$ Moreover, previous studies have showed no difference in pain scores between nSILC and TPLC groups. ${ }^{7,813}$ There were no significant differences visual analogue scale scores of the three groups in this study.

A previous study described a statistically significant shorter length of hospital stay for patients who underwent SILC ${ }^{6}$ and another study reported that these patients experienced improved recovery and shortened length of hospitalization compared with conventional open cholecystectomy. ${ }^{13}$ On the other hand, one study reported no difference in length of hospital stay between patients undergoing SILC and TPLC. ${ }^{3}$ This study showed that the days of hospitalization between the three groups were not significantly different. This may vary depending on the nature of the hospital and the characteristics of the patient.

Previous studies have reported post-operative complications such as bile leakage, bile duct injury, surgical site bleeding, urinary and pulmonary infection, wound infection, seroma, hematoma, incisional hernia, and duodenal perforation. . $^{12,14-16}$ Like the present study, many studies have found no significant difference in complication rate between SILC and conventional laparoscopic cholecystectomy. ${ }^{3,13,14}$ Conversely, one study showed that the incidence of postoperative complications in patients who underwent SILC was lower in conventional laparoscopic cholecystectomy. ${ }^{12}$ Recently, some articles have been published to report the feasibility and safety of SILC compared to conventional laparoscopic cholecystectomy., ${ }^{2,11}$ In this study, there were 4 out of 135 (two cases in the pSILC group, one case in the nSILC group, and one case in the TPLC group) postoperative complications. Postoperative complications may be due to differences in operative capacity, operative environment, or patient status.

Most clinical features and surgical outcomes were similar between pSILC and nSILC. However, there was a difference in operation time. Results of this study show that nSILC operation time was longer than that of TPLC, but shorter than that of pSILC. The operation time for nSILC was 1.15 times that of TPLC but was 0.76 times less than that of pSILC. The same results were found in other studies. ${ }^{2,6,10} \mathrm{Kim}$ et al. ${ }^{2}$ reported that the nSILC group had longer operative times than the TPLC group. Another study described that operative time was significantly longer in the pSILC group than in the four-port LC group. ${ }^{6,10}$ Van der Linden et al. ${ }^{3}$ reported that the disadvantages of single-port surgery were often referred to as timeconsuming surgery. Although nSILC method takes longer than TPLC, nSILC has an anatomical view that is an advantage of TPLC. That is, nSILC overcomes the disadvantage of not achieving anatomical vision of pSILC. Therefore, nSILC feasible surgical procedure in patients with benign gallbladder disease compared with TPLC and it is an effective approach to overcome the limitations of pSILC. Recently, single incision robotic cholecystectomy (SIRC) has been introduced to improve the merit of minimally invasive surgery. The operation 
time (skin to skin) of SIRC is similar to that of SILC. SIRC is just as safe and effective as SILC. However, the total cost of SIRC is significantly higher than that of SICL. ${ }^{17,18}$ Therefore, it is expected that SILC will be mainly performed in small and medium hospitals in the future.

This study has several limitations to consider. Because it was a retrospective, single institutional research study, data from only a small sample size could be collected. Thus, this limits the generalizability of our findings. Data from a larger sample size will be needed to determine the true rate of postoperative complications, postoperative pain, and length of hospital stay. Future prospective randomized controlled trials will be required to significantly determine the efficacy and safety of nSILC.

\section{ORCID}

Chai-Won Kim, https://orcid.org/0000-0001-9465-1151

Soo-Ho Lee, https://orcid.org/0000-0002-5359-0804

Kee-Hwan Kim, https://orcid.org/0000-0001-6219-6027

\section{AUTHORS' CONTRIBUTIONS}

Conceptualization: KHK. Formal analysis: SHL. Methodology: KHK, CWK. Writing-original draft: KHK, CWK. Writing-review and editing: KHK.

\section{CONFLICT OF INTEREST}

None.

\section{FUNDING}

None.

\section{ACKNOWLEDGMENTS}

None.

\section{REFERENCES}

1) Cha MG, Kim TS, Kim KH, An CH, Kim JS. The Effectiveness of a Snake Liver Retractor during Needlescopic Grasper Assisted Sinlge-Incision Laparoscopic Cholecystectomy in the Aspect of Securing a Critical View of Safety. J Minim Invasive Surg 2013;16: 34-38.

2) Kim MJ, Kim TS, Kim KH, An CH, Kim JS. Safety and feasibility of needlescopic grasper-assisted single-incision laparoscopic cholecystectomy in patients with acute cholecystitis: comparison with three-port laparoscopic cholecystectomy. J Laparoendosc Adv
Surg Tech A 2014;24:523-527.

3) van der Linden YT, Bosscha K, Prins HA, Lips DJ. Single-port laparoscopic cholecystectomy vs standard laparoscopic cholecystectomy: A non-randomized, age-matched single center trial. World J Gastrointest Surg 2015;7:145-151.

4) Kim SJ, Kim KH, An CH, Kim JS. Innovative technique of needlescopic grasper-assisted single-incision laparoscopic common bile duct exploration: A comparative study. World J Gastroenterol 2015;21:12857-12864.

5) Tagaya N, Suzuki A, Sugamata Y, Oya M. Single-incision laparoscopic cholecystectomy with needlescope via an another port. World J Minim Access Surg 2012;1:7-11.

6) Culp BL, Cedillo VE, Arnold DT. Single-incision laparoscopic cholecystectomy versus traditional four-port cholecystectomy. Proc (Bayl Univ Med Cent) 2012;25:319-323.

7) Kim TS, Kim KH, An CH, Kim JS. Single center experiences of needle-scopic grasper assisted single incision laparoscopic cholecystectomy for gallbladder benign disease: comparison with conventional 3-port laparoscopic cholecystectomy. Ann Surg Treat Res 2016;91:233-238.

8) Chang WB, Han HS, Yoon YS, Cho JY, Choi Y. Single incision laparoscopic cholecystectomy for patients with Mirizzi syndrome. Ann Surg Treat Res 2018;94:106-111.

9) Shussman N, Schlager A, Elazary R, et al. Single-incision laparoscopic cholecystectomy: lessons learned for success. Surg Endosc 2011;25:404-407.

10) Sasaki A, Ogawa M, Tono C, Obara S, Hosoi N, Wakabayashi G. Single-port versus multiport laparoscopic cholecystectomy: a prospective randomized clinical trial. Surg Laparosc Endosc Percutan Tech 2012;22:396-399.

11) Barband A, Fakhree MB, Kakaei F, Daryani A. Single-incision laparoscopic cholecystectomy using glove port in comparison with standard laparoscopic cholecystectomy SILC using glove port. Surg Laparosc Endosc Percutan Tech 2012;22:17-20.

12) Cheon SU, Moon JI, Choi IS. Risk factors for prolonged operative time in single-incision laparoscopic cholecystectomy. Ann Surg Treat Res 2015;89:247-253.

13) Deveci U, Barbaros U, Kapakli MS, et al. The comparison of single incision laparoscopic cholecystectomy and three port laparoscopic cholecystectomy: prospective randomized study. J Korean Surg Soc 2013;85:275-282.

14) Wagner MJ, Kern H, Hapfelmeier A, Mehler J, Schoenberg MH. Single-port cholecystectomy versus multi-port cholecystectomy: a prospective cohort study with 222 patients. World J Surg 2013;37: 991-998.

15) Lirici MM, Tierno SM, Ponzano C. Single-incision laparoscopic cholecystectomy: does it work? A systematic review. Surg Endosc 2016;30:4389-4399.

16) Lee YJ, Moon JI, Choi IS, et al. A large-cohort comparison between single incision laparoscopic cholecystectomy and conven- 
tional laparoscopic cholecystectomy from a single center; 2080 cases. Ann Hepatobiliary Pancreat Surg 2018;22:367-373.

17) Sun N, Zhang JL, Zhang CS, Li XH, Shi Y. Single-incision robotic cholecystectomy versus single-incision laparoscopic cholecystectomy: A systematic review and meta-analysis. Medicine (Balti- more) 2018;97:e12103.

18) Migliore M, Arezzo A, Arolfo S, Passera R, Morino M. Safety of single-incision robotic cholecystectomy for benign gallbladder disease: a systematic review. Surg Endosc 2018;32:4716-4727. 